Supporting Information

\title{
Polyene-Free Photoluminescent Polymers via Hydrothermal Hydrolysis of Polyacrylonitrile in Neutral Water
}

Mingkang Sun ${ }^{\dagger}$, ", Eric Gottlieb ${ }^{\dagger}$ I, ฯ, Rui Yuan†, Supriya Ghosh», Han Wang ${ }^{\ddagger}$, Ryan Selhorst ${ }^{\dagger}$, Alicia Huggett ${ }^{\dagger}$, Xiangsha $\mathrm{Du}^{\dagger}$, Rongguan Yin ${ }^{\dagger}$, David H. Waldeck ${ }^{\S}$, Krzysztof Matyjaszewski ${ }^{*}$,, Tomasz Kowalewski*, $\dagger$

${ }^{\dagger}$ Department of Chemistry, ${ }^{+D e p a r t m e n t ~ o f ~ M a t e r i a l s ~ S c i e n c e ~ a n d ~ E n g i n e e r i n g, ~ C a r n e g i e ~ M e l l o n ~ U n i v e r s i t y, ~}$ Pittsburgh, Pennsylvania 15213, United States.

§Department of Chemistry, University of Pittsburgh, 219 Parkman Ave, Pittsburgh, Pennsylvania 15260, United States.

'These authors contributed equally to this work.

*Corresponding authors: Tomasz Kowalewski (tomek@andrew.cmu.edu), Krzysztof Matyjaszewski (km3b@andrew.cmu.edu).

"Current address: Department of Chemical and Biomolecular Engineering, University of Delaware, 150 Academy Street, Colburn Laboratory, Newark, Delaware 19716, United States. 


\section{Table of Contents}

1. Materials, Instrumentation and Characterization Methods..........................................................

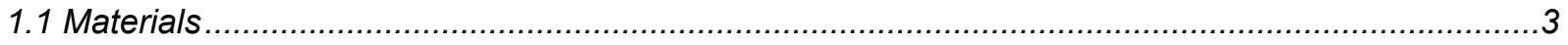

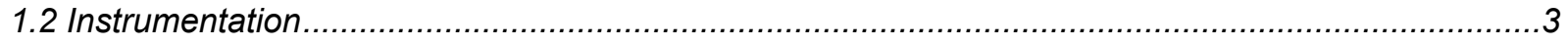

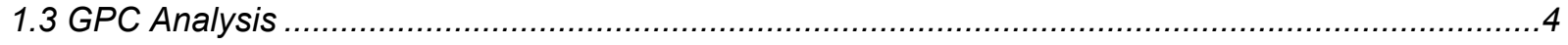

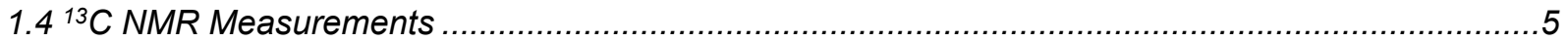

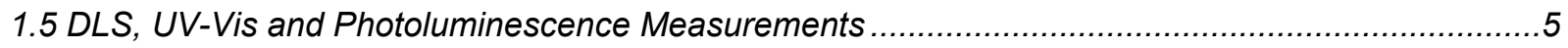

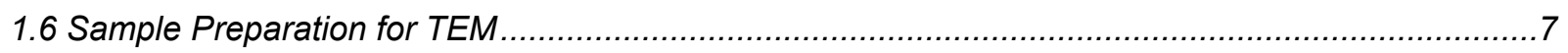

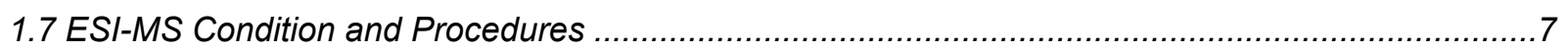

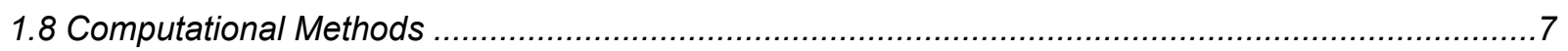

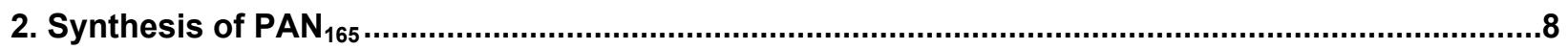

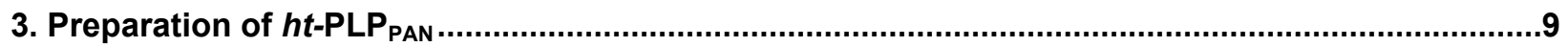

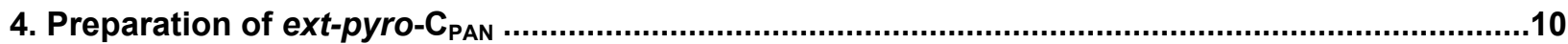

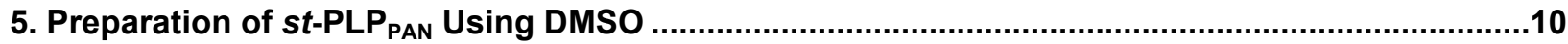

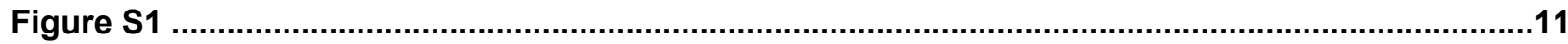

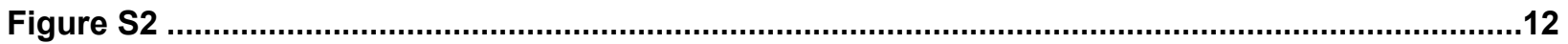

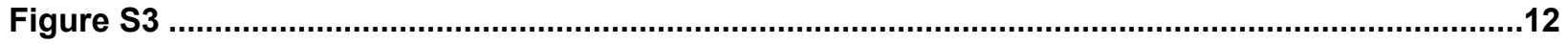

Figure S4

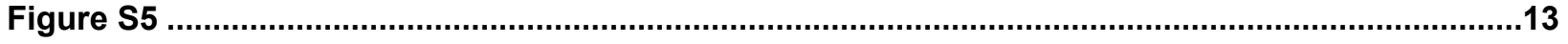

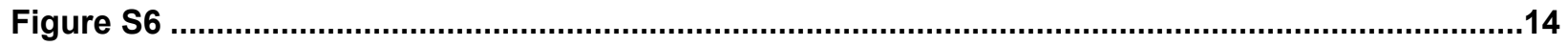

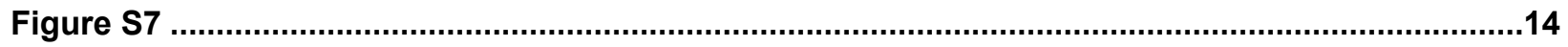

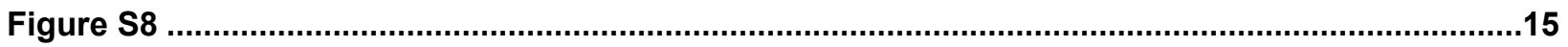

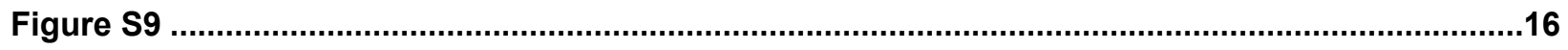

Figure S10

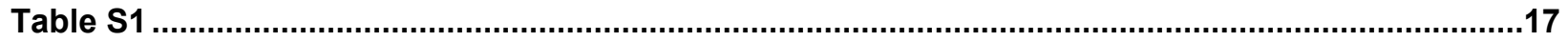

Appendix: Cartesian Coordinates of Optimized Structures .........................................................17

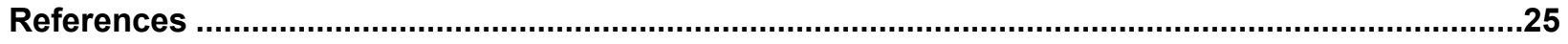




\section{Materials, Instrumentation and Characterization Methods}

\subsection{Materials}

Acrylonitrile (AN, Sigma-Aldrich, $>99 \%$ ) was passed through a column containing basic alumina $\left(\sim 7 \mathrm{~cm}^{3}\right.$ for $20 \mathrm{~mL}$ monomer) to remove the inhibitor. Azobisisobutyronitrile (AIBN, Sigma-Aldrich, 98\%) were recrystallized in anisole and stored at $4{ }^{\circ} \mathrm{C}$ in dark. Deionized water (DI water) was obtained from MilliporeSigma Milli-Q water purification system. Tris(2pyridylmethyl)amine (TPMA) was synthesized based on previously reported methods ${ }^{1,2}$. 2Bromopropionitrile (BPN, Sigma-Aldrich, 97\%), 2-bromoisobutyryl bromide (BiBBr, Fisher, $>98 \%$ ), rhodamine-6G (Sigma-Aldrich, 99\%), copper(II) bromide $\left(\mathrm{CuBr}_{2}, \mathrm{Acros}\right.$ Organics, $>99 \%$ ), dimethylformamide (DMF, Fisher, 99.9\%), dimethyl sulfoxide (DMSO, Fisher, 99.9\%), methanol (MeOH, Fisher, 99.9\%), deuterated DMSO (DMSO-d $\mathrm{d}_{6}, 99.9 \%$, Cambridge Isotope Laboratories), deuterated $\mathrm{CHCl}_{3}\left(\mathrm{CDCl}_{3}, 99.5 \%\right.$ Cambridge Isotope Laboratories $)$ and deuterium oxide (99.5\%, Cambridge Isotope Laboratories) were used as received. TEM grids (model number: CF300-Cu, standard thickness, 300 square mesh) were purchased from Electron Microscopy Sciences.

\subsection{Instrumentation}

${ }^{1} \mathrm{H}$ NMR was conducted on a Bruker $500 \mathrm{MHz}$ AVANCE III NMR spectrometer. ${ }^{13} \mathrm{C}$ NMR was conducted on a Bruker $500 \mathrm{MHz}$ NEO NMR spectrometer. DMF GPC was performed based on a refractive index (RI) detector. The GPC was equipped with an Agilent 1260 Infinity II pump and a Wyatt Optilab T-rEX RI detector, with PSS GRAM analytical column (10 $\mu \mathrm{m}$ particle size) and LiBr-containing HPLC grade DMF as the eluent (LiBr: $0.05 \mathrm{~mol} \mathrm{~L}^{-1}$ ). Solvent evaporation was performed on a Biotage V10 rapid solvent removal system. Fourier-transform infrared spectroscopy (FTIR) was carried out on a PerkinElmer Frontier FT-IR spectrometer. X-Ray 
photoelectron spectroscopy (XPS) was performed on a Thermo Scientific ESCALAB 250Xi Xray photoelectron spectrometer microprobe with $900 \mu \mathrm{m}$ spot size and flood gun as electron source. The element composition was calculated from CasaXPS software. UV-Vis spectra were taken on an Agilent Cary 60 UV-Vis spectrometer and recorded by Cary WinUV software. Photoluminescence spectra and excitation-emission matrices were taken on a Horiba FluoroMax 3 fluorometer and recorded by FluorEssence software. Time-resolved photoluminescence decays were measured using the time-correlated single photon counting (TSCPC) technique with a PicoHarp 300 TCSPC module (PicoQuant GmbH). ESI-MS was conducted with Thermo Exactive EMR Orbitrap Mass Spectrometer using a conventional electrospray ionization (ESI) source. Dynamic light scattering (DLS) and zeta potential measurement were performed on a Malvern Zetasizer Nano system. Quartz cuvettes with four clear sides were used for the size measurement and plastic capillary cuvettes with two electrodes were used for the zeta potential measurement. Transmission electron microscopy (TEM) was performed on a JEOL JEM-2000EX TEM using a Gatan ES500W Erlangshen camera, with an accelerating voltage of $200 \mathrm{kV}$ and working current of $112 \mu \mathrm{A}$. Sonication was performed using a Sharpertek CD-4800 ultrasonic cleaner, with frequency set to $60 \mathrm{~Hz}$ and power set to $60 \mathrm{~W}$.

\subsection{GPC Analysis}

In a typical measurement, $5 \mathrm{mg}$ polymer was dissolved in $2 \mathrm{~mL}$ HPLC grade DMF. One drop of toluene was added as internal calibration standard for RI signal. Injection volume was 50 $\mu \mathrm{L}$. Columns were kept at $50{ }^{\circ} \mathrm{C}$ in a column thermostat oven and flow rate in DMF was set to be $1 \mathrm{~mL} \min ^{-1}$. Molecular weight (MW) and dispersity index $(\nexists)$ were calculated using PSS WinGPC software and an RI calibration based on PMMA Easivial standards (with toluene as internal standard) from Agilent. 


\section{$1.4{ }^{13} \mathrm{C}$ NMR Measurements}

In a typical measurement, $20 \mathrm{mg} h t$-PLP $\mathrm{PAN}_{\mathrm{PAN}}$ was dissolved in $0.5 \mathrm{~mL}$ deuterium oxide and was measured with 1024 cycles on the Bruker $500 \mathrm{MHz}$ NMR spectrometer. For ext-pyro-C $\mathrm{C}_{\mathrm{PAN}}$, same concentration was used in $\mathrm{CDCl}_{3}$. For $s t-\mathrm{PLP}_{\mathrm{PAN}}, \mathrm{d}_{6}-\mathrm{DMSO}$ was used as the solvent. For PAN, $100 \mathrm{mg}$ PAN $_{165}$ was dissolved in $0.5 \mathrm{~mL} \mathrm{~d}_{6}$-DMSO and measured with 256 cycles.

\subsection{DLS, UV-Vis and Photoluminescence Measurements}

For DLS and zeta potential measurement, $h t-$ PLP $_{\text {PAN }}$ solutions with concentration of 0.5 $\mathrm{mg} / \mathrm{mL}$ in DI water were prepared and passed through a $0.22 \mu \mathrm{m}$ syringe filter with polyethersulfone (PES) membrane to remove a small portion of insoluble residues. UV-Vis spectra and luminescence decay curves were measured with sample concentration of $0.5 \mathrm{mg} / \mathrm{mL}$ in DI water. Single-emission and excitation-emission matrix photoluminescence spectra were measured in DI water with the concentration of $0.1 \mathrm{mg} / \mathrm{mL}$. The horizontal lines in the excitation-emission matrix (Figure 3e) are caused by automatically filtering the Rayleigh scattering signals from incident light.

For the luminescence decay curve, emission wavelength was set to $500 \mathrm{~nm}$, and the excitation wavelength was set to $378 \mathrm{~nm}$ using a diode laser. The average lifetime was calculated based on the following equation:

$$
\tau_{\text {ave }}=\frac{\sum b_{i} \tau_{i}^{2}}{\sum b_{i} \tau_{i}}
$$

Where $\tau_{\text {ave }}$ is the average lifetime, and $b_{i}$ is the pre-exponential factor corresponding to the $i^{t h}$ lifetime $\tau_{i}$. All lifetime components and pre-exponential factors are listed in Table $\mathbf{S 1 .}$ 
For the photoluminescence quantum yield (PLQY) measurement, a relative PLQY was calculated using an ethanol solution of rhodamine $6 \mathrm{G}$ as the reference. The calculation is based on the following equation:

$$
P L Q Y_{x}=P L Q Y_{r e f} \frac{\eta_{x}^{2} I_{x} A_{r e f}}{\eta_{r e f}{ }^{2} A_{x} I_{r e f}}
$$

Where $P L Q Y_{x}$ is the PLQY of an unknown substance $x$, and $P L Q Y_{r e f}$ is the PLQY of the reference $\left(95 \%\right.$ for rhodamine $\left.6 \mathrm{G}^{3}\right) \cdot \eta_{x}$ and $\eta_{\text {ref }}$ are refractive indices of the solvent for unknown substance and the reference, respectively. $I_{x}$ and $I_{r e f}$ are integration values of the emission spectrum of the unknown substance $x$ and the reference, respectively. $A_{x}$ and $A_{r e f}$ are the absolute absorbances at excitation wavelength for $x$ and the reference. The excitation wavelengths used for $h t$-PLP $P_{\text {PAN }}$ and rhodamine-6G are $365 \mathrm{~nm}$ and $480 \mathrm{~nm}$, respectively.

\subsection{Sample Preparation for TEM}

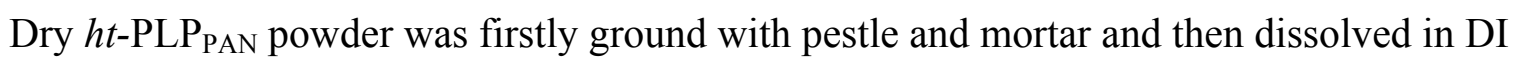
water with a concentration of $\sim 1 \mathrm{mg} / \mathrm{mL}$. Then the solution was sonicated for $5 \mathrm{~min}$ and passed through the $0.22 \mu \mathrm{m}$ syringe filter with PES membrane to remove a small amount of insoluble residues. The solution was then drop-casted on the copper grid supported by a piece of filter paper. The grid was dried in ambient condition for $10 \mathrm{~min}$ and the film of $h t$-PLP $P_{\text {PAN }}$ was formed on the graphene film of the grid.

\subsection{ESI-MS Condition and Procedures}

$h t$-PLP PAN was dissolved in 1:1 (vol) methanol: water with a concentration of $5 \mu \mathrm{M}$ with $50 \mu \mathrm{M}$ ammonium hydroxide. The resolution of the mass spectrometer was set to 70,000 . Spray 
voltage was set to $2.5 \mathrm{~V}$ and capillary temperature was set to $275^{\circ} \mathrm{C}$. The spectra were obtained with a flow rate of $10 \mu \mathrm{L} / \mathrm{min}$.

\subsection{Computational Methods}

DFT and TD-DFT calculations were performed with Gaussian 09 package Rev. $\mathrm{A} 02^{4}$. The Cartesian coordinates of optimized structures are listed in the Appendix. Structures of N3-N10 represents the major luminophores in $h t$-PLP $P_{\text {PAN }}$, rather than the entire polymer. Since our main goal is to demonstrate the changes in electronic structures of oligomers with different degrees of polymerizations, isotactic isomers were mainly used to maintain consistency. However, it should be noted that similar structures containing $\mathrm{C}=\mathrm{N}$ bonds can be formed from PAN with other tacticities as well. The Cartesian coordinates of a model molecule exhibiting atactic aliphatic backbones, N4a, are listed along N4 in the Appendix. Optimizations of N3 to N10 were performed at the b3lyp/6-31g-d,p level ${ }^{5,6}$. TD-DFT was performed at the cam-b3lyp/6-31g-d,p $\mathrm{p}^{7}$ level using the polarizable continuum model (PCM) $)^{8}$ and water as the solvent to simulate the environment in aqueous solutions. Natural transition orbital (NTO) analysis was carried out using Multiwfn package $^{9}$ with checkpoint files from TD-DFT calculations.

The experimental absorption profiles $I_{\text {exp }}$ were fitted to a linear combination of simulated spectra of isotactic oligomers containing $n$ nitrogen atoms, $I_{N}(N=3,4,5,6,7,8,9$ and 10 for N3N10 oligomers) according to the formula: $I_{\text {exp }}=k_{0}+k_{N} \times I_{N}$, where $k_{0}$ is a constant and $k_{N}$ are fitting coefficients for respective oligomers. The fitting was performed using a custom program written in Mathematica (Wolfram, Inc). Normalized fitting coefficients for respective oligomers are shown in Figure S6. 


\section{Synthesis of $\mathrm{PAN}_{165}$}

Synthesis of PAN was based on previous methods (initiator for continuous activator regeneration ATRP, or ICAR-ATRP) ${ }^{10,11} .20 \mathrm{~mL}$ of AN (0.31 mol, $\left.500 \mathrm{eq}\right), 6.9 \mathrm{mg} \mathrm{CuBr}_{2}(0.031$ mmol, $0.05 \mathrm{eq})$ and $26.8 \mathrm{mg}$ TPMA (0.092 mmol, $0.15 \mathrm{eq})$ were charged into a Schlenk flask containing $25 \mathrm{~mL}$ of DMSO and $2.5 \mathrm{~mL}$ of DMF ( ${ }^{1} \mathrm{H}$ NMR internal standard), and was purged with $\mathrm{N}_{2}$ for $20 \mathrm{~min} .53 .1 \mu \mathrm{L} \mathrm{BPN}(0.61 \mathrm{mmol}, 1 \mathrm{eq})$ was then injected and the mixture was further degassed for $10 \mathrm{~min}$. Finally, $10.1 \mathrm{mg}$ of AIBN ( $0.061 \mathrm{mmol}, 0.1 \mathrm{eq})$ was added and the Schlenk flask was quickly immersed in an oil bath that was pre-heated to $65^{\circ} \mathrm{C}$ to start polymerization. 0.2 $\mathrm{mL}$ reaction mixture was withdrawn from the reaction vessel using $\mathrm{N}_{2}$-purged syringe and needle to measure the polymerization conversion via ${ }^{1} \mathrm{H}$ NMR. The reaction was quenched at $6 \mathrm{~h}$ by exposure to air. After stirring in air for $1 \mathrm{~h}$, the mixture was precipitated in $1 \mathrm{~L} \mathrm{MeOH}$ and the filtered solid was dried in vacuum at room temperature overnight to give dry linear PAN. GPC trace of the PAN precursor is shown below:

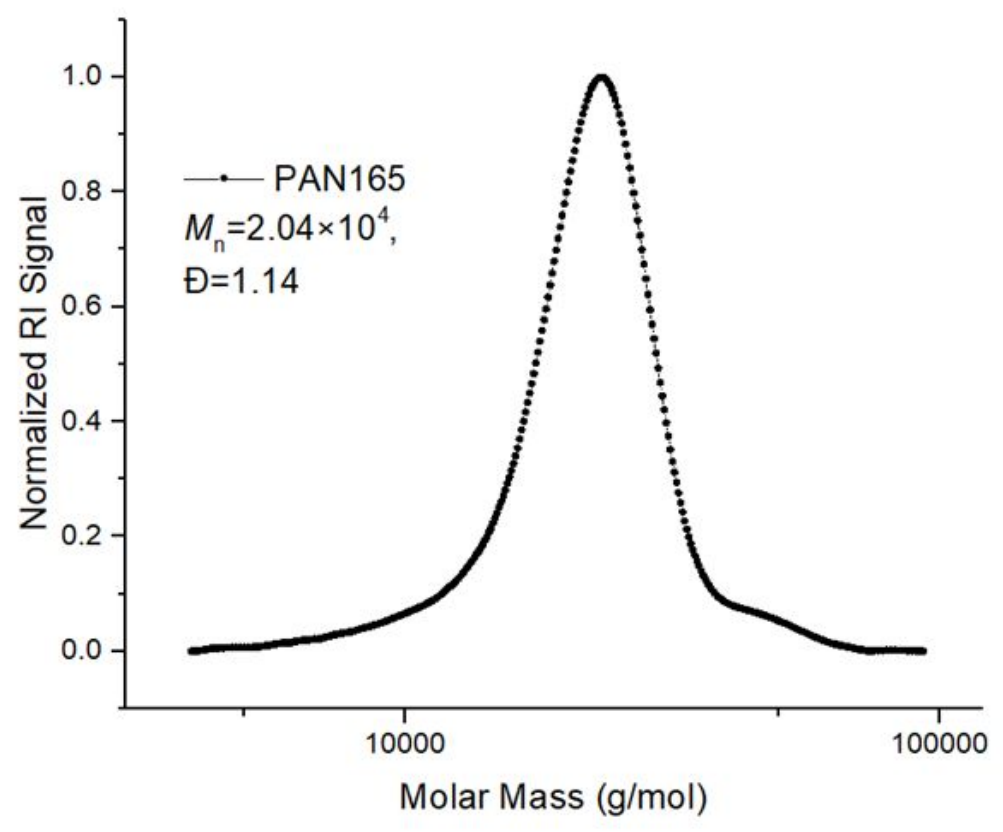




\section{Preparation of $h t-$ PLP $_{\mathrm{PAN}}$}

In a typical procedure with a $5 \mathrm{mg} / \mathrm{mL}$ suspension, $50 \mathrm{mg}$ polymer powder was ball-milled to fine powder and was charged in a $20 \mathrm{~mL}$ glass vial containing $10 \mathrm{~mL}$ deionized water. The suspension was slightly sonicated and then immediately transferred to a $25 \mathrm{~mL}$ autoclave reactor with high-temperature resistant liner. The autoclave reactor was then securely sealed and placed in an oven that was pre-heated to $180^{\circ} \mathrm{C}$. After $12 \mathrm{~h}$, the heating was turned off and the oven was cooled down to room temperature naturally. The dark brown solution was able to pass through a $0.22 \mu \mathrm{m}$ syringe filter with a polyethersulfone (PES) membrane. The solution was directly dried by vacuum evaporation of water to yield brown solid $h t-$ PLP PAN $_{\text {Por }}$. XPS analysis of hydrothermal reaction product at different hydrothermal time, the hydrothermal reaction was stopped at $4 \mathrm{~h}$ and $8 \mathrm{~h}$, respectively. Then the reaction mixture (both water-soluble and water-insoluble product) were dried by evaporation and ground to fine powders which is subject to XPS analysis.

\section{Preparation of ext-pyro- $\mathrm{C}_{\mathrm{PAN}}$}

PAN $\mathrm{N}_{165}$ was placed in a glass furnace and was heated up to $250^{\circ} \mathrm{C}$ in $\mathrm{N}_{2}$ with a step of 5 ${ }^{\circ} \mathrm{C} / \mathrm{min}$. Then thermally annealed dark red powder was ground to fine powder and dispersed in $\mathrm{CHCl}_{3}$ (typically, $20 \mathrm{~mL} \mathrm{CHCl}_{3}$ was used to disperse powders generated from $250 \mathrm{mg}$ PAN). The suspension was sonicated for $1 \mathrm{~h}$, followed by removal of insoluble graphitic carbon chunks by filtering $\left(0.22 \mu \mathrm{m}\right.$ filter with polytetrafluoroethylene/PTFE membrane). Finally, $\mathrm{CHCl}_{3}$ was removed by evaporation and gave yellow powder ext-pyro- $\mathrm{C}_{\mathrm{PAN}}(\mathrm{C}$ refers to the carbonaceous nature of the product). The average yield is estimated to be approx. $10 \%$ by weight, as most PAN substrates are transformed into insoluble species. 


\section{Preparation of $s t-$ PLP $_{\mathrm{PAN}}$ Using DMSO}

$50 \mathrm{mg} \mathrm{PAN}_{165}$ was dissolved in $10 \mathrm{~mL}$ DMSO. The solution was transferred to a $25 \mathrm{~mL}$ autoclave reactor with PTFE liner. The autoclave reactor was then sealed and placed in an oven that is pre-heated to $150{ }^{\circ} \mathrm{C}$ (caution is needed to avoid high temperatures). The reason for using this temperature is that DMSO violently burns and destroys the autoclave at higher temperatures, even if the temperature is still below the boiling point of DMSO. The reaction was stopped at 10 $\mathrm{h}$ by cooling down to room temperature naturally. The product $s t$ PLP PAN $_{\text {was }}$ obtained by concentrating the solution with air overnight, followed by drying with a V10 rapid evaporator and in a vacuum oven at room temperature for another $24 \mathrm{~h}$.
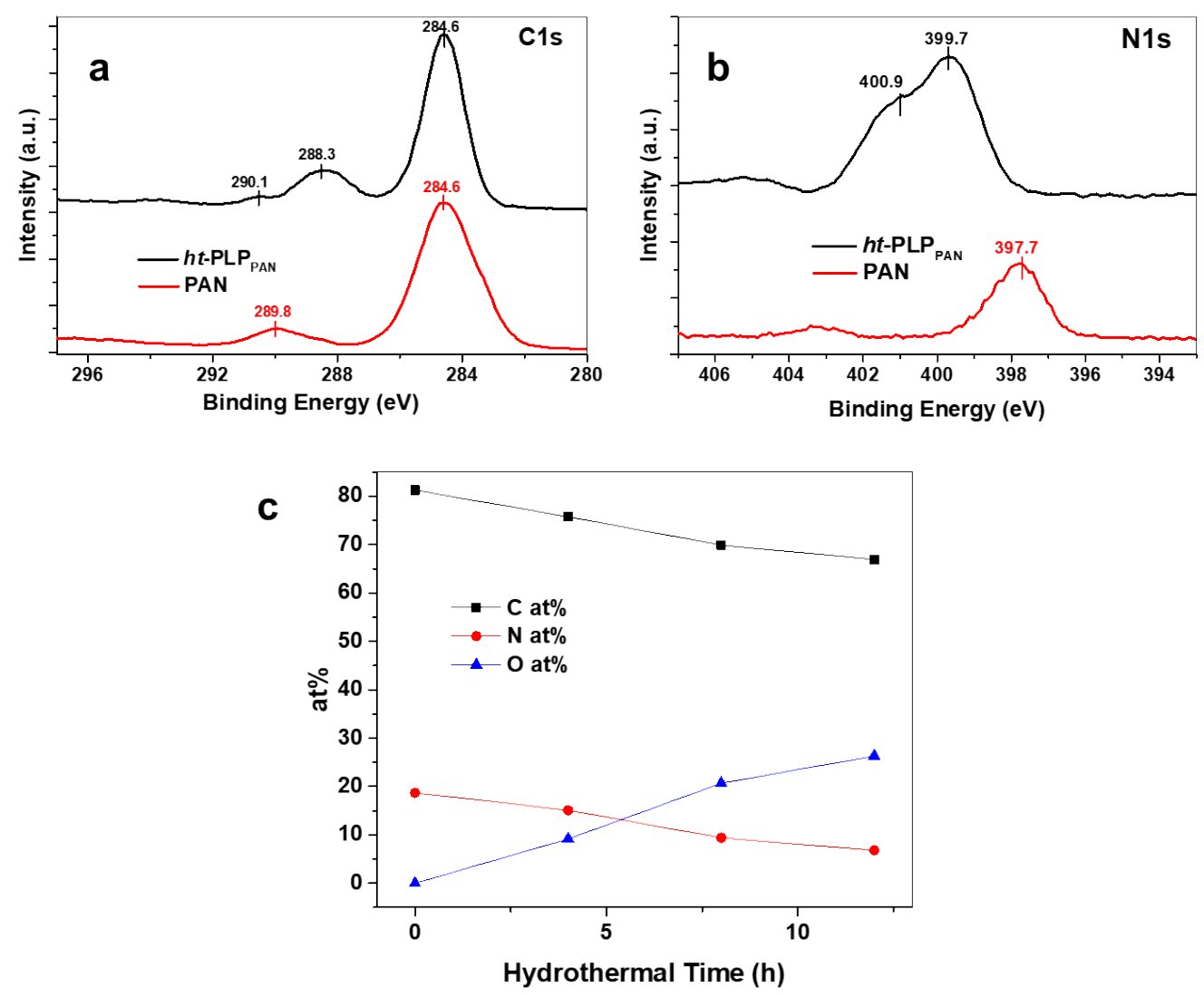

Figure S1 (a) XPS C1s scans for $h t$-PLP $\mathrm{PAN}_{\mathrm{PAN}}$ and PAN. (b) XPS N1s scans for $h t$-PLP $\mathrm{PAN}_{\mathrm{PAN}}$ and PAN. (c) Atomic composition of the hydrothermal reaction mixture at different stages of the reaction. 


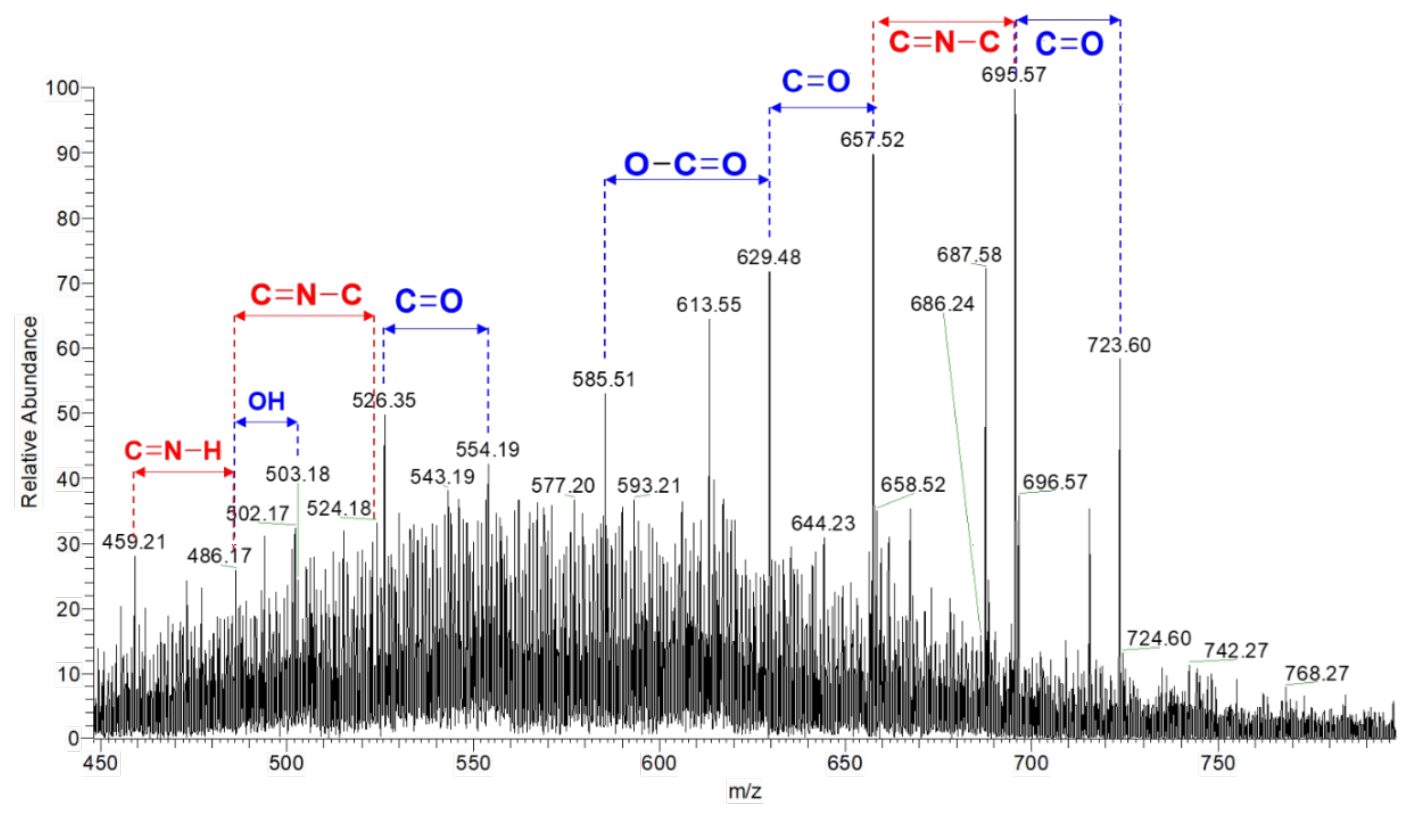

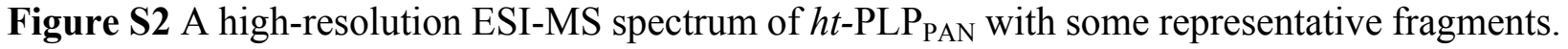

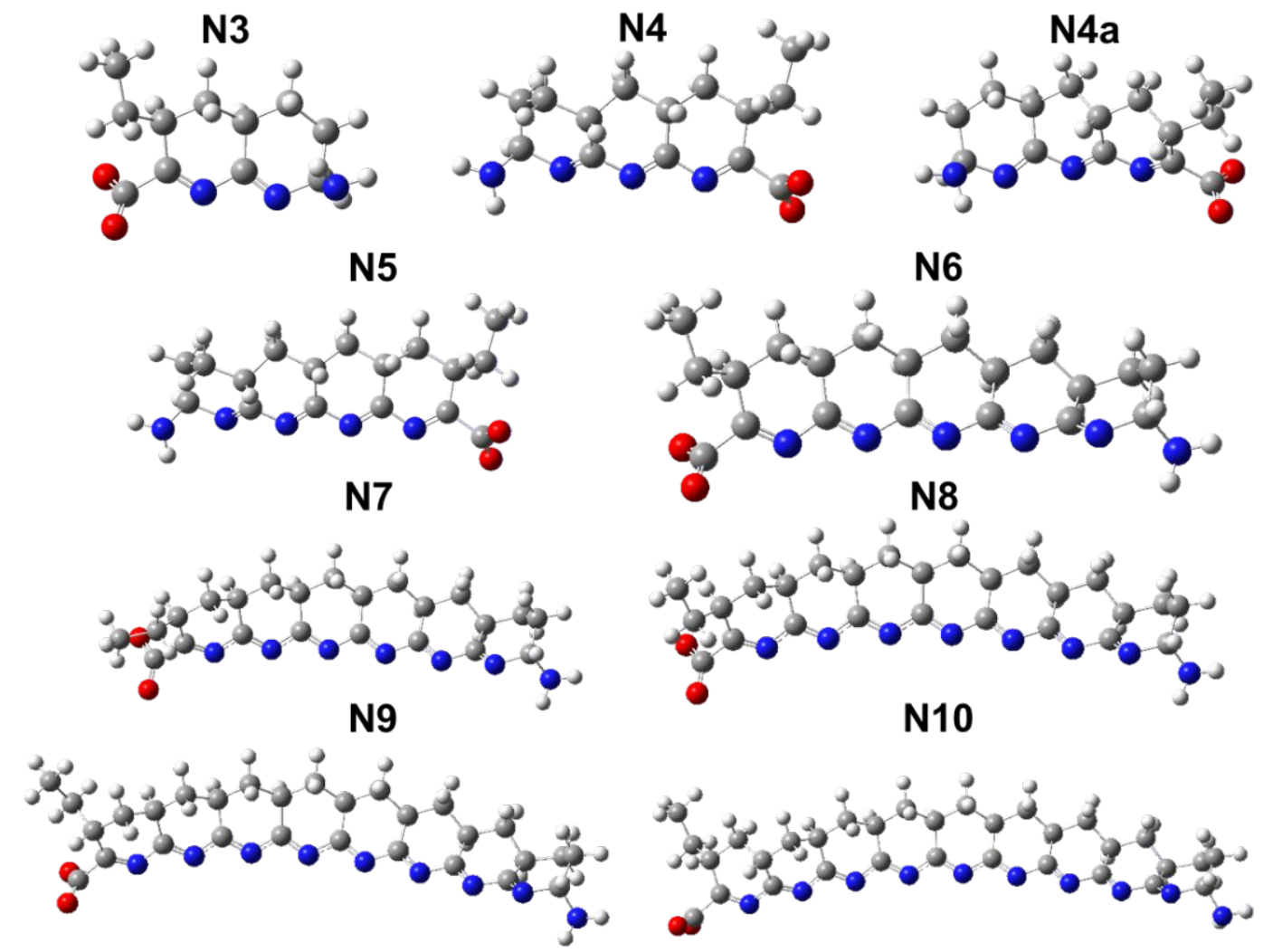

Figure S3 Structures of N3 to N10, modeled by DFT at b3lyp/6-31g-d,p level with PCM water solvation model. 

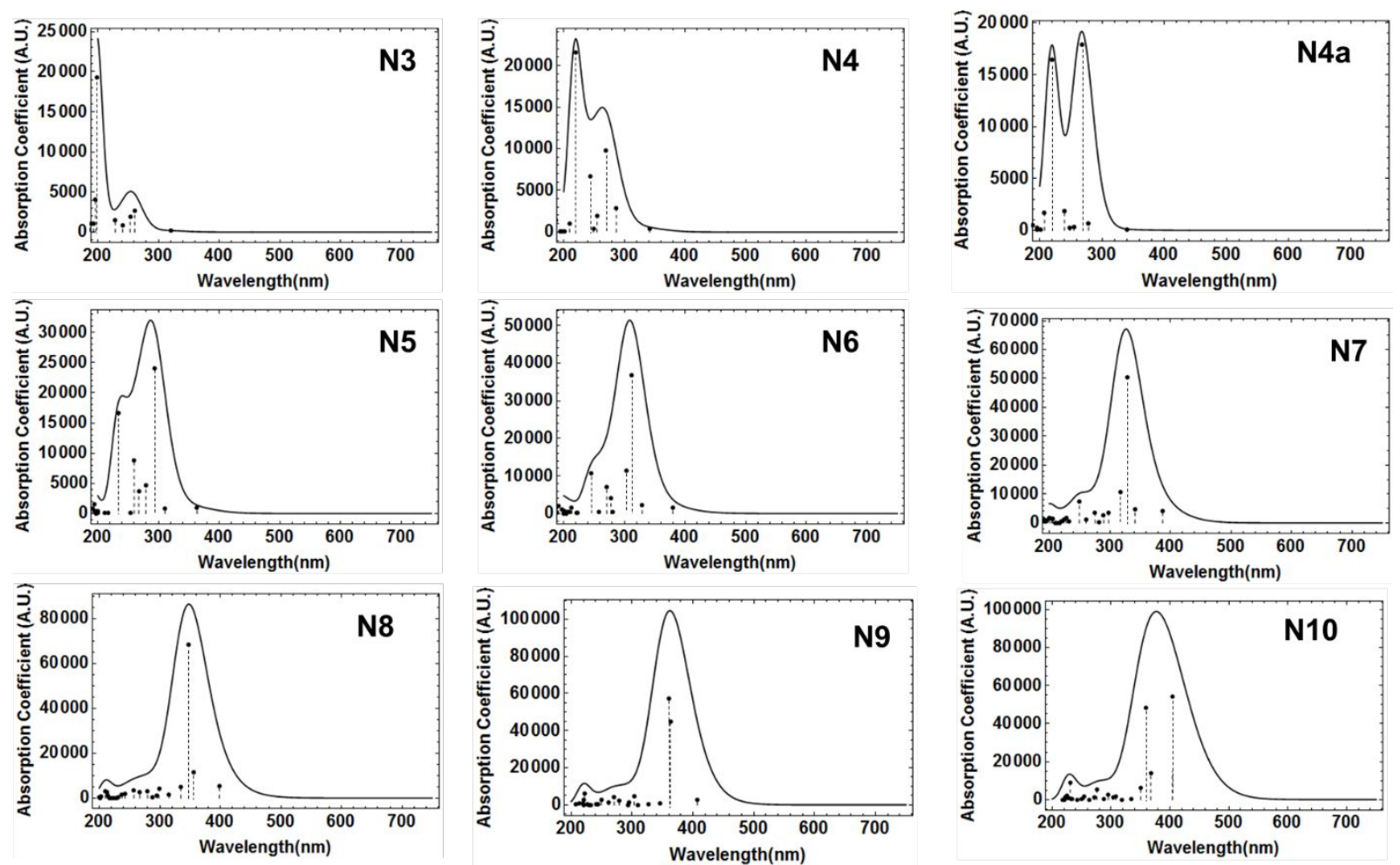

Figure S4 Simulated UV-Vis absorption spectra with transitions (the height of each transition is normalized to the oscillator strength) for N3 to N10. Structures were optimized by DFT at b3lyp/6$31 \mathrm{~g}-\mathrm{d}, \mathrm{p}$ level using PCM water solvation model. TD-DFT calculations were performed at camb3lyp/6-31g-d,p level using PCM water solvation model and covered 24 lowest-energy excitations.

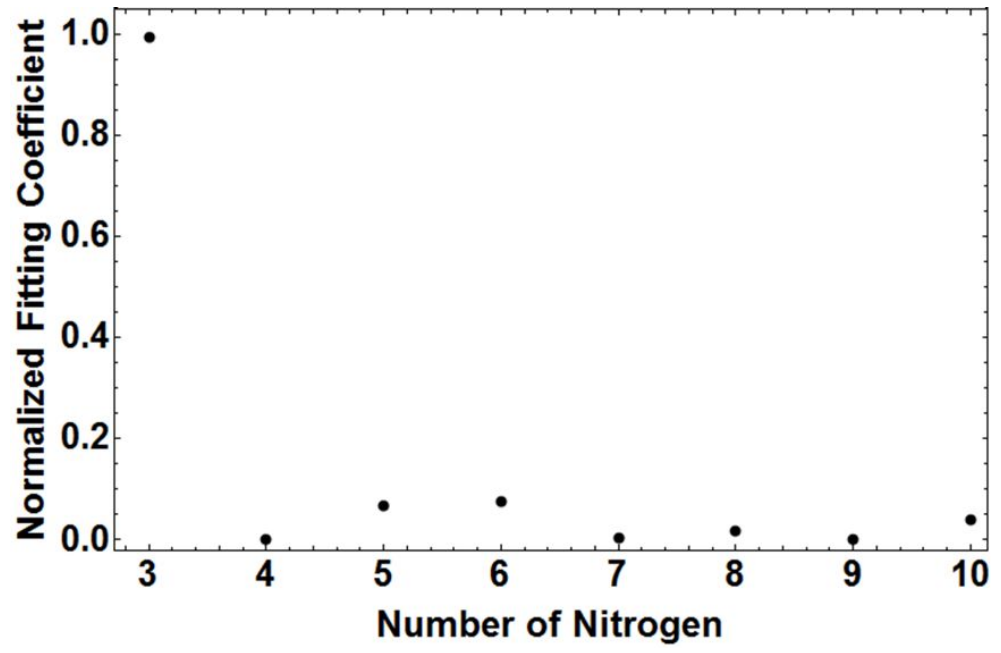

Figure S5 Normalized fitting coefficients for N3 to N10. 


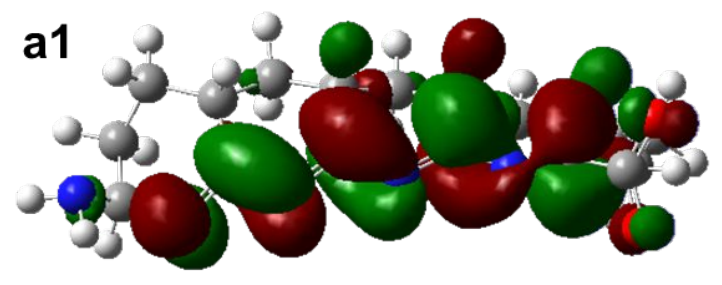

b1
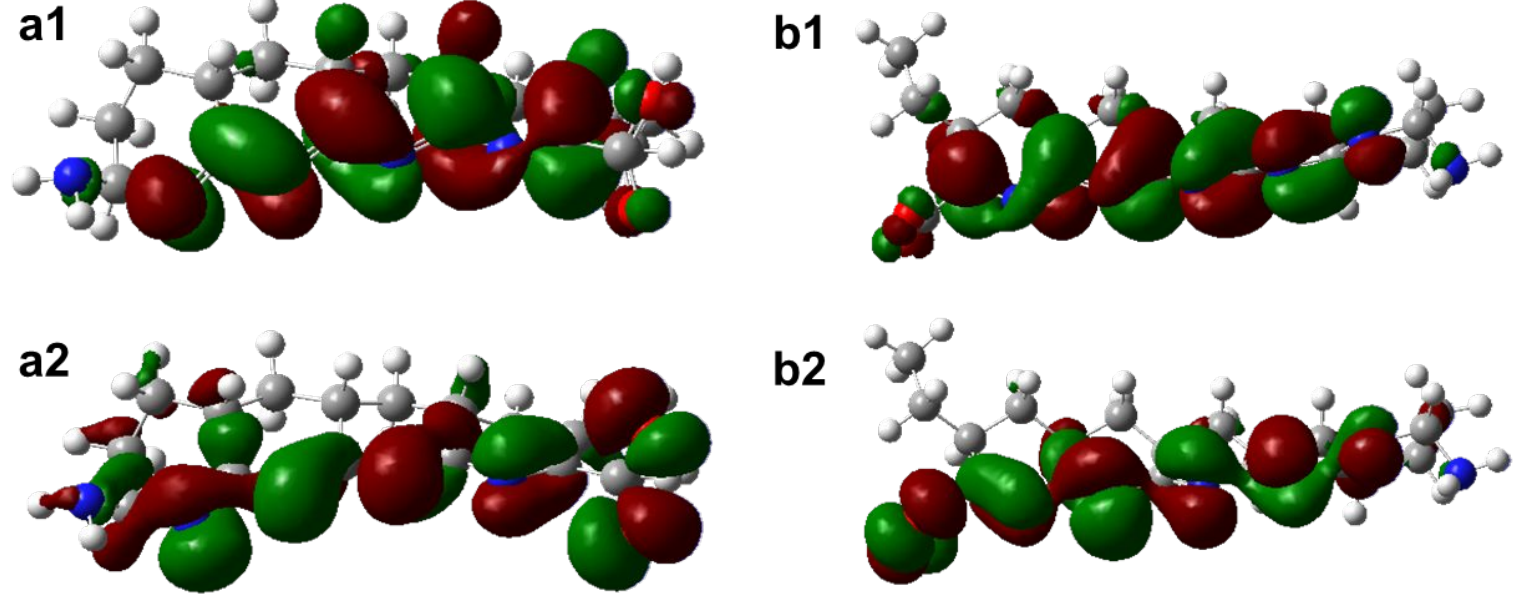

b2

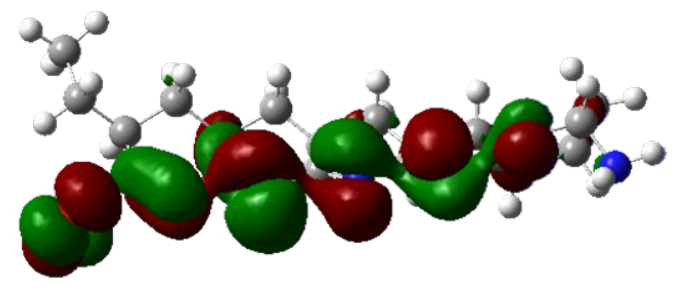

Figure S6 (a1) NTO initial ("hole") and (a2) final ("electron") state for the transition (transition 3) at $293.3 \mathrm{~nm}$ for N5. (b1) NTO "hole" and (b2) "electron" for the transition at $312.0 \mathrm{~nm}$ (transition 3) for N6.

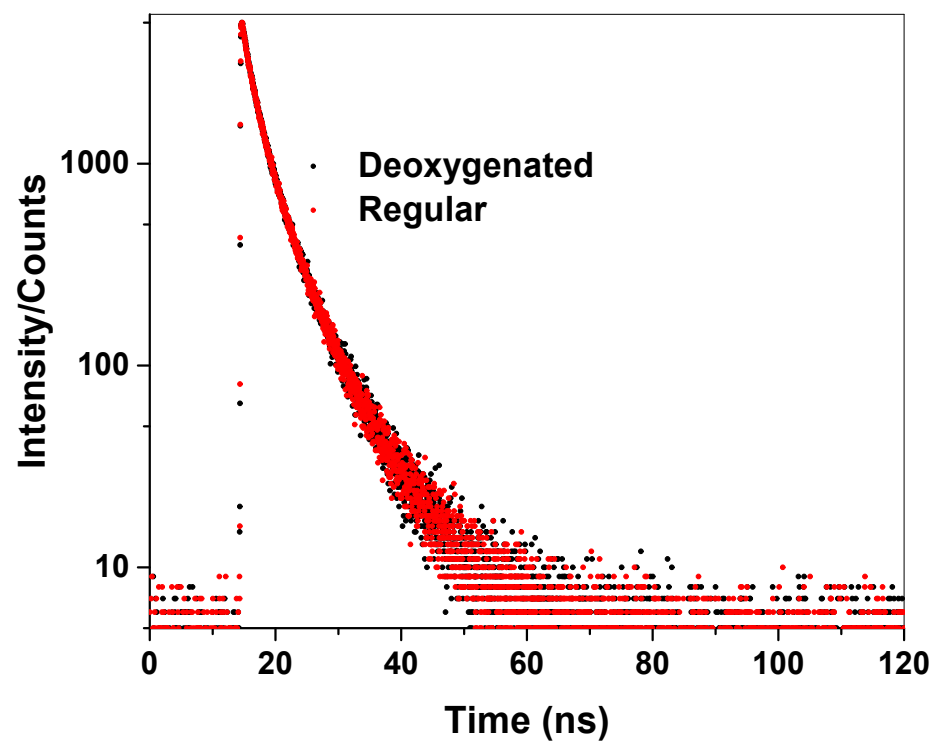

Figure S7 Lifetime decay curve of $h t$-PLP $\mathrm{PAN}_{\mathrm{PAN}}$ in Ar-deoxygenated water (blue) and regular water (red). 

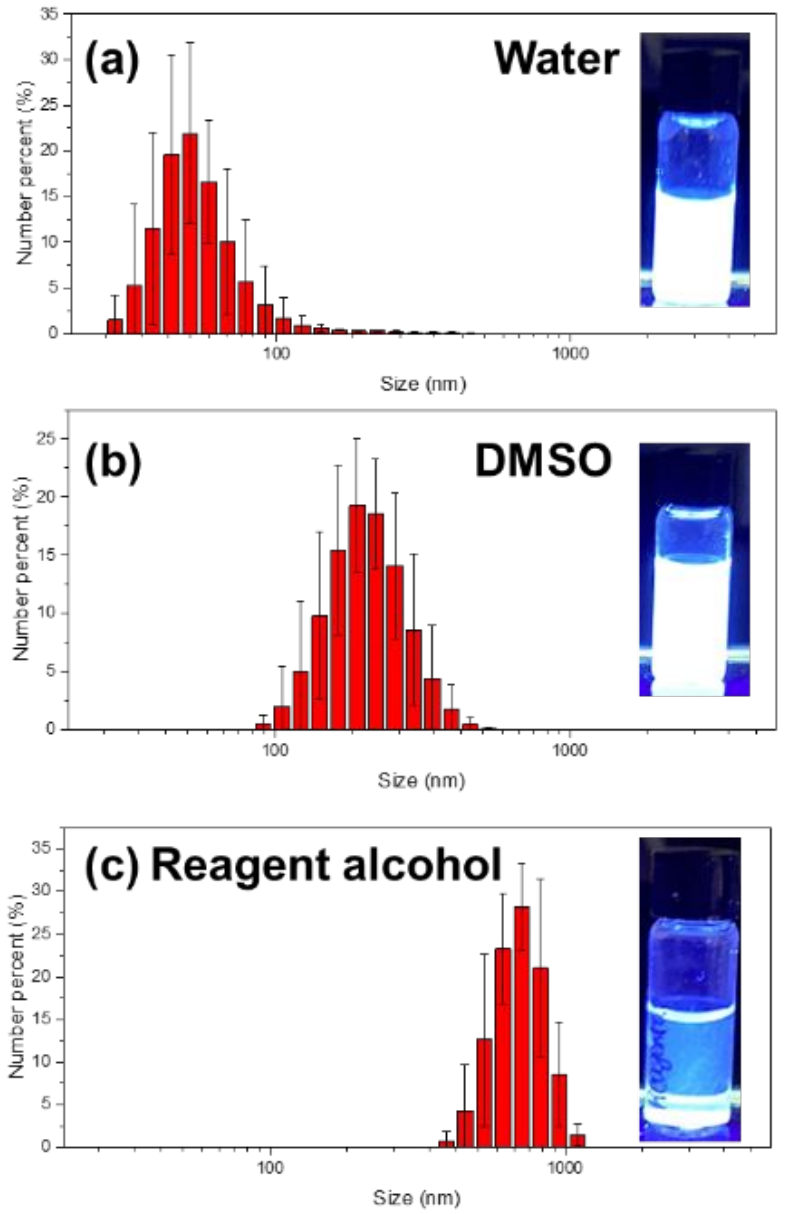

Figure S8 DLS number fraction distribution and photographs (insets) of luminescing $h t$-PLP PAN dissolved in (a) DI water, (b) DMSO and (c) reagent alcohol with a concentration of $0.5 \mathrm{mg} / \mathrm{mL}$. Luminescence of solutions was driven by excitation with UV light (365 nm). 

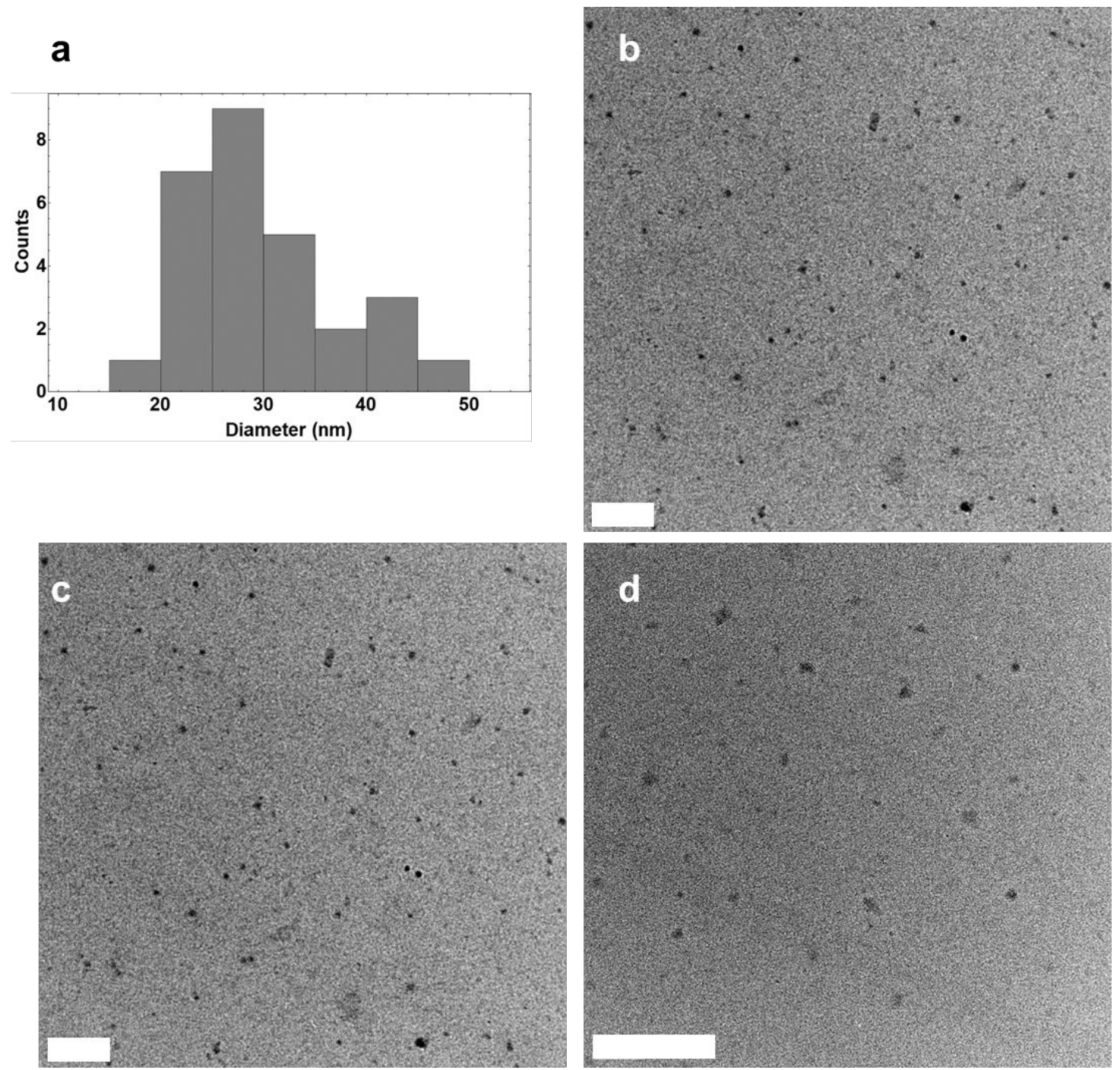

Figure S9 (a) Distribution of particle diameter of Figure 3a, measured by randomly selecting approx. 30 aggregates. (b-d) Additional TEM pictures of $h t$-PLP PAN $_{\text {an }}$ at different degrees of magnification. All scale bars: $200 \mathrm{~nm}$. 


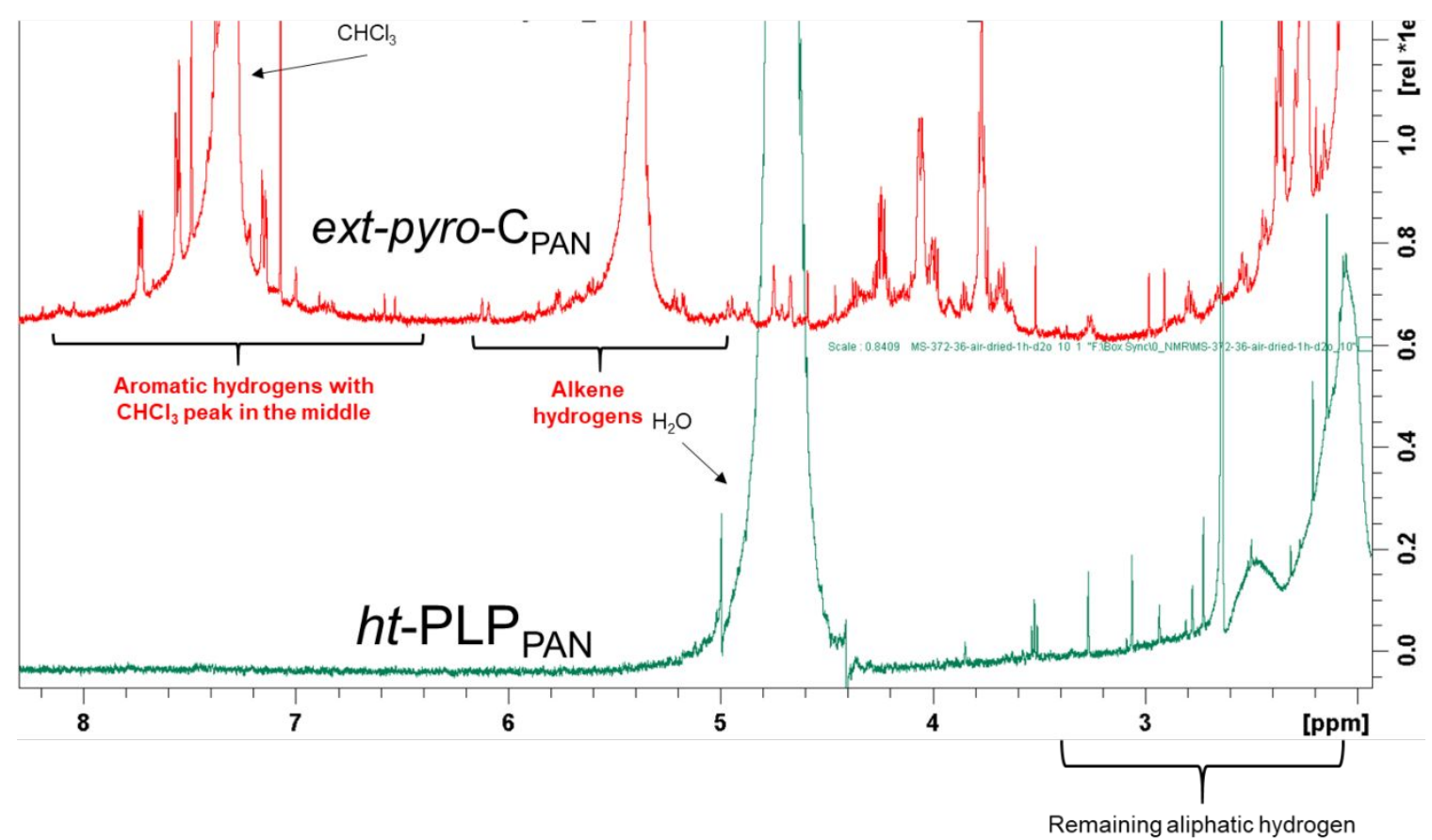

Figure S10 ${ }^{1} \mathrm{H}$ NMR spectra of ext-pyro- $\mathrm{C}_{\mathrm{PAN}}$ (red, top) and $h t-\mathrm{PLP}_{\mathrm{PAN}}$ (green, bottom) in $\mathrm{CDCl}_{3}$ and $\mathrm{D}_{2} \mathrm{O}$, respectively.

Table S1 Deconvolution of different components of the photoluminescence lifetime decay of the solution of $h t-\mathrm{PLP}_{\mathrm{PAN}}$. Emission wavelength was fixed at $500 \mathrm{~nm}$ and excitation wavelength was set to $378 \mathrm{~nm}$.

\section{Component Component lifetime}

$\tau_{1}$

$\tau_{2}$

$\tau_{3}$
1.246

3.477

8.88

\section{Pre-exponential factor $b_{\mathrm{i}}$}

0.1834

0.14445

0.0192

\section{Appendix: Cartesian Coordinates of Optimized Structures}

N3

$\mathrm{N}, 3.917647,-0.527257,1.407742$

C, $3.400659,-0.742879,0.044298$

$\mathrm{N}, 2.069735,-1.344236,0.176746$

C, $1.022118,-0.671276,-0.14289$

N, $-0.204026,-1.363146,-0.01453$ 
C, $3.455428,0.492413,-0.876775$

C, $0.980742,0.752215,-0.683354$

C, $2.328789,1.462336,-0.528739$

C, $-0.176027,1.500374,-0.006601$

C, $-1.507237,0.774803,-0.221465$

C, $-2.633035,1.287089,0.704466$

C, $-2.951561,2.775195,0.525911$

$\mathrm{H}, 2.442865,1.809736,0.507445$

$\mathrm{H}, 2.35757,2.357594,-1.159255$

$\mathrm{H}, 0.749109,0.66989,-1.757407$

$\mathrm{H}, 0.03168,1.576209,1.070377$

$\mathrm{H},-3.536927,0.702939,0.505045$

H, $-2.354195,1.091704,1.748628$

$\mathrm{H},-3.794047,3.068909,1.160413$

H, 3.347594, 0.166358, -1.920199

$\mathrm{H},-1.840756,0.936791,-1.257521$

$\mathrm{H},-0.224044,2.524953,-0.390319$

$\mathrm{H},-3.223466,2.997675,-0.512505$

C, $-1.33065,-0.734443,-0.095239$

O, $-3.265509,-1.41621,-1.216217$

C, $-2.60853,-1.585644,-0.15365$

$\mathrm{O},-2.855969,-2.335516,0.819249$

$\mathrm{H},-2.102776,3.413216,0.791463$

H, $4.042079,-1.520588,-0.393375$

$\mathrm{H}, 4.439568,0.96724,-0.791491$

$\mathrm{H}, 3.391416,0.226812,1.847855$

H, 4.878493, -0.194262, 1.341114

N4

C, $-4.403445,1.045217,-0.383956$

C, $-4.430938,-0.405668,-0.882406$

N, $-3.11939,-1.058393,-0.904435$

C, $-2.19243,-0.627321,-0.125746$

$\mathrm{N},-0.946062,-1.270913,-0.241906$

C, $0.126756,-0.64859,0.131219$

$\mathrm{N}, 1.320635,-1.372369,0.05167$

C, $-2.296285,0.495707,0.89896$

C, $0.190731,0.770105,0.672765$

C, $-3.699543,1.123667,0.969588$

C, $-1.159838,1.485636,0.578789$

C, $1.336478,1.500349,-0.043993$

C, 2.66201, 0.752055, 0.139366

C, 3.750231, 1.188064, -0.868298

C, 4.11164, 2.67397, -0.776629

$\mathrm{H},-4.300293,0.576849,1.701836$

$\mathrm{H},-3.626752,2.159664,1.319567$

$\mathrm{H},-5.426426,1.433964,-0.317411$

$\mathrm{H},-1.299005,1.895803,-0.430273$

$\mathrm{H},-1.184867,2.332521,1.273484$

$\mathrm{H}, 0.461323,0.676198,1.73647$

H, 1.09648, 1.57413, -1.113823

H, 4.65061, 0.589911, - 0.694763

H, 3.408805, 0.951474, - 1.884649

$\mathrm{H}, 4.92049,2.917595,-1.472782$

$\mathrm{H},-2.062945,0.046599,1.874917$

$\mathrm{H}, 3.052962,0.955445,1.147808$

$\mathrm{H}, 1.413343,2.524968,0.334036$

$\mathrm{H}, 4.449702,2.935522,0.232673$

H, -3.87946, 1.655954, -1.13004

C, $2.460702,-0.757162,0.111725$

$\mathrm{H},-4.769305,-0.40161,-1.932217$

O, 4.297791, -1.479123, 1.352693

C, 3.724239, - $1.61374,0.240385$

$\mathrm{O}, 4.043414,-2.321781,-0.742422$

H, 3.262006, 3.31897, -1.021241

$\mathrm{N},-5.321813,-1.222425,-0.034652$

$\mathrm{H},-6.287449,-0.968514,-0.24163$

H, -5.224297, -2.193247, -0.329488

\section{N4a}


C, $-4.772818,0.449815,-0.402028$

C, $-4.466884,-0.752618,0.505235$

$\mathrm{N},-3.142705,-1.354848,0.346001$

C, $-2.220235,-0.748984,-0.31103$

N, $-0.980159,-1.405811,-0.397321$

C, $0.088667,-0.680484,-0.313055$

$\mathrm{N}, 1.30906,-1.350873,-0.408459$

C, $-2.371738,0.580194,-1.059314$

C, $0.010889,0.824414,-0.111954$

C, $-1.045206,1.381652,-1.084177$

C, $1.377119,1.495833,-0.262372$

C, 2.465607, 0.69016, 0.461887

C, 3.874212, 1.3025, 0.32855

C, $4.010759,2.694852,0.952942$

$\mathrm{H},-5.652162,0.979435,-0.018131$

$\mathrm{H},-0.618224,1.364475,-2.092691$

H, -1.240936, 2.432904, -0.845823

$\mathrm{H},-0.343174,0.981546,0.918519$

$\mathrm{H}, 1.640083,1.561881,-1.327206$

$\mathrm{H}, 4.583233,0.622363,0.810136$

$\mathrm{H}, 4.149047,1.341628,-0.73333$

H, 5.046634, 3.043479, 0.89181

H, 2.217294, 0.656334, 1.535492

$\mathrm{H}, 1.326419,2.521021,0.116008$

H, 3.726944, 2.682138, 2.011749

$\mathrm{H},-5.032982,0.084384,-1.403962$

C, $2.401545,-0.749007,-0.043255$

$\mathrm{H},-5.182959,-1.557742,0.266787$

$\mathrm{O}, 4.101782,-1.908219,1.056213$

C, 3.690034, $-1.569353,-0.083562$

$\mathrm{O}, 4.183058,-1.796666,-1.21223$

$\mathrm{H}, 3.385403,3.438821,0.449765$

$\mathrm{N},-4.572351,-0.342807,1.920482$

$\mathrm{H},-5.558878,-0.237864,2.155207$

$\mathrm{H},-4.232866,-1.116749,2.490263$

H, $-2.619812,0.30517,-2.094363$

C, $-3.558454,1.369735,-0.492389$

H, $-3.307527,1.744693,0.507028$

H, $-3.762162,2.239275,-1.126911$

N5

C, 5.636367, 0.96446, 0.418778

C, $5.567164,-0.418692,1.078987$

$\mathrm{N}, 4.223957,-1.003133,1.105918$

C, 3.36005, $-0.626224,0.231874$

$\mathrm{N}, 2.077246,-1.188629,0.362949$

C, $1.052647,-0.577259,-0.144803$

$\mathrm{N},-0.171376,-1.227375,-0.005733$

C, 3.575247, 0.355266, -0.912873

C, $1.096362,0.752151,-0.888758$

C, $5.008539,0.914027,-0.972739$

C, $2.469678,1.420988,-0.789558$

C, $-0.063944,1.622194,-0.388668$

C, $-1.394045,0.891207,-0.578543$

C, $-2.543458,1.488318,0.248187$

H, 5.621004, 0.262412, -1.60229

H, 5.002451, 1.904573, -1.441514

$\mathrm{H}, 6.679102,1.299113,0.366644$

$\mathrm{H}, 2.564929,1.946635,0.169708$

$\mathrm{H}, 2.575976,2.173634,-1.578479$

$\mathrm{H}, 0.907069,0.510339,-1.946957$

$\mathrm{H}, 0.087907,1.845608,0.675714$

$\mathrm{H},-2.276346,1.438354,1.312796$

H, $3.377119,-0.202489,-1.839311$

$\mathrm{H},-1.675475,0.938083,-1.642363$

H, $-0.079258,2.581531,-0.917158$

$\mathrm{H}, 5.105047,1.679219,1.059883$

C, $-1.279279,-0.583011,-0.2345$

H, 5.855589, $-0.30934,2.137926$

N, 6.453312, $-1.367301,0.376299$ 
H, 7.42005, $-1.134799,0.602432$

$\mathrm{H}, 6.29368,-2.292261,0.773726$

H, $-2.659968,2.548198,0.00069$

C, $-3.851561,0.727205,0.009324$

$\mathrm{H},-4.274861,1.032319,-0.960164$

$\mathrm{N},-2.442701,-1.344713,-0.187038$

C, $-3.605258,-0.765568,-0.143493$

C, $-4.840625,-1.647815,-0.325239$

$\mathrm{O},-5.12725,-2.424693,0.61427$

O, -5.425987, - $1.457933,-1.421904$

C, $-4.924451,1.01092,1.086042$

$\mathrm{H},-5.811402,0.407599,0.868057$

H, $-4.548045,0.670763,2.059552$

C, $-5.330004,2.485621,1.173308$

$\mathrm{H},-4.493517,3.124784,1.472143$

H, $-5.70139,2.850104,0.208673$

H, $-6.127407,2.621975,1.91065$

N6

C, $6.857341,0.828926,0.515013$

C, $6.700765,-0.509034,1.24921$

$\mathrm{N}, 5.33097,-1.029414,1.257914$

C, 4.518275, $-0.667027,0.330152$

N, 3.204996, -1.158233, 0.448442

C, $2.229187,-0.534582,-0.136283$

N, $0.970774,-1.110263,0.0155$

C, $4.822622,0.231578,-0.861783$

C, $2.367168,0.733041,-0.970679$

C, $6.280925,0.724056,-0.895315$

C, $3.762825,1.349065,-0.850694$

C, $1.22447,1.684736,-0.597659$

C, $-0.123384,0.995015,-0.809961$

C, $-1.299515,1.72676,-0.151687$

$\mathrm{H}, 6.88675,0.011277,-1.461589$

$\mathrm{H}, 6.336894,1.684835,-1.419378$

H, 7.915409, 1.114665, 0.485937

$\mathrm{H}, 3.841022,1.928546,0.078621$

$\mathrm{H}, 3.935437,2.046099,-1.678021$

H, 2.218941, 0.421434, -2.017268

$\mathrm{H}, 1.329221,1.980947,0.454567$

$\mathrm{H},-1.125626,1.784175,0.930997$

H, 4.636044, $-0.373751,-1.760341$

$\mathrm{H},-0.319761,0.936054,-1.89252$

$\mathrm{H}, 1.278269,2.601158,-1.195137$

$\mathrm{H}, 6.335205,1.601834,1.093094$

C, $-0.101679,-0.442471,-0.307538$

$\mathrm{H}, 6.956093,-0.35151,2.310551$

$\mathrm{N}, 7.565399,-1.535425,0.634885$

$\mathrm{H}, 8.533989,-1.329542,0.878201$

$\mathrm{H}, 7.354,-2.42679,1.081804$

H, $-1.362085,2.756122,-0.520192$

C, $-2.607647,0.984704,-0.4239$

H, $-2.911634,1.170382,-1.466225$

$\mathrm{N},-1.291868,-1.143336,-0.198211$

C, $-2.433442,-0.51632,-0.293429$

C, $-3.75807,1.418828,0.497057$

$\mathrm{H},-3.466727,1.233496,1.539993$

$\mathrm{N},-3.561489,-1.323379,-0.309671$

C, $-4.74559,-0.80097,-0.168915$

C, $-5.042678,0.648967,0.177011$

$\mathrm{H},-5.487736,1.058456,-0.743461$

$\mathrm{H},-3.916346,2.497212,0.398847$

C, $-5.948986,-1.702829,-0.433116$

O, $-6.204509,-2.569814,0.43332$

$\mathrm{O},-6.543882,-1.43238,-1.506694$

C, $-6.111615,0.756204,1.288948$

$\mathrm{H},-6.984201,0.163241,0.997276$

$\mathrm{H},-5.717056,0.298795,2.205385$

C, $-6.554933,2.194286,1.575428$

H, - - 7.350556, 2.207688, 2.326936 
$\mathrm{H},-5.733752,2.809845,1.955571$

H, -6.942374, 2.67564, 0.670179

N7

C, $8.100673,0.414617,0.652231$

C, $7.831819,-0.992068,1.202532$

N, $6.427507,-1.404686,1.132259$

C, $5.657295,-0.858882,0.259514$

$\mathrm{N}, 4.310224,-1.261632,0.300604$

C, 3.393071, $-0.489788,-0.195835$

$\mathrm{N}, 2.094105,-0.985921,-0.14333$

C, 6.044364, 0.169723, -0.795585

C, $3.637819,0.87189,-0.834182$

C, $7.537265,0.541586,-0.761517$

C, 5.07512, 1.354964, - 0.625772

C, $2.564593,1.841871,-0.325596$

C, $1.174162,1.29583,-0.650273$

C, $0.039514,2.00138,0.101542$

$\mathrm{H}, 8.090756,-0.139519,-1.414143$

H, 7.678015, 1.554485, -1.155472

H, $9.177869,0.61815,0.665368$

H, 5.186897, 1.788219, 0.377037

H, 5.310755, 2.146944, -1.345037

H, 3.47856, 0.729941, -1.915291

$\mathrm{H}, 2.673349,1.966504,0.76003$

$\mathrm{H}, 0.185434,1.869134,1.181814$

H, 5.81965, $-0.287361,-1.769963$

$\mathrm{H}, 0.995476,1.418512,-1.730459$

$\mathrm{H}, 2.697129,2.831285,-0.776443$

H, 7.631079, 1.143402, 1.324955

C, 1.079464, $-0.198723,-0.374819$

H, 8.07939, - $0.994467,2.277365$

$\mathrm{N}, 8.629202,-1.99166,0.465501$

H, 9.605157, -1.896737, 0.745127

$\mathrm{H}, 8.340512,-2.915343,0.785447$

$\mathrm{H}, 0.063088,3.078335,-0.095448$

C, $-1.309889,1.41712,-0.314115$

$\mathrm{H},-1.551849,1.77822,-1.326246$

$\mathrm{N},-0.15855,-0.816131,-0.389258$

C, $-1.254573,-0.101341,-0.408635$

C, $-2.461253,1.805024,0.623379$

$\mathrm{H},-2.232708,1.443974,1.634647$

$\mathrm{N},-2.425455,-0.813966,-0.561611$

C, $-3.577416,-0.218505,-0.383273$

C, $-3.775337,1.189715,0.141166$

$\mathrm{H},-4.168152,1.785084,-0.696827$

$\mathrm{H},-2.549893,2.894559,0.685987$

C, $-4.850871,1.113538,1.237192$

$\mathrm{H},-4.450302,0.524682,2.072796$

$\mathrm{H},-5.056346,2.11573,1.628453$

$\mathrm{N},-4.699245,-0.936709,-0.743012$

C, $-6.152494,0.470939,0.735197$

H, $-6.760893,1.228995,0.221544$

C, $-5.881667,-0.575075,-0.332814$

C, $-7.074577,-1.18487,-1.067926$

O, $-7.309055,-2.401533,-0.888607$

O, -7.669726, -0.342201, -1.78509

C, $-6.979367,-0.061911,1.936413$

H, $-6.93101,0.714899,2.709858$

$\mathrm{H},-6.464301,-0.936375,2.354772$

C, $-8.448591,-0.402422,1.669178$

H, $-8.547373,-1.268342,1.011641$

$\mathrm{H},-8.953832,-0.636756,2.612019$

H, $-8.975451,0.440978,1.209949$

N8

C, $-9.280095,-0.272227,0.761166$

C, $-8.956938,1.090414,1.386467$

$\mathrm{N},-7.535252,1.441188,1.344257$

C, $-6.791433,0.925789,0.430789$ 
$\mathrm{N},-5.4281,1.265506,0.501047$

C, $-4.542479,0.519271,-0.084798$

$\mathrm{N},-3.226213,0.957975,0.022262$

C, $-7.22893,0.000261,-0.698401$

C, $-4.84503,-0.748974,-0.872865$

C, $-8.730695,-0.341627,-0.662355$

C, $-6.286494,-1.217182,-0.664987$

C, $-3.781545,-1.800237,-0.537427$

C, $-2.391334,-1.244658,-0.846277$

C, $-1.244087,-2.09546,-0.291829$

H, $-9.276528,0.379576,-1.276668$

$\mathrm{H},-8.896901,-1.331571,-1.102049$

$\mathrm{H},-10.3638,-0.438203,0.77089$

$\mathrm{H},-6.380869,-1.737849,0.2972$

H, $-6.562462,-1.934,-1.446038$

$\mathrm{H},-4.725608,-0.478237,-1.934663$

$\mathrm{H},-3.850368,-2.063607,0.526447$

$\mathrm{H},-1.331283,-2.156459,0.801051$

$\mathrm{H},-7.016546,0.53802,-1.633713$

$\mathrm{H},-2.276084,-1.191054,-1.941069$

H, $-3.957305,-2.718685,-1.107805$

$\mathrm{H},-8.833209,-1.052732,1.389846$

C, $-2.239505,0.182269,-0.337104$

H, $-9.212208,1.046929,2.458554$

$\mathrm{N},-9.703984,2.161885,0.699136$

$\mathrm{H},-10.686384,2.09123,0.963068$

$\mathrm{H},-9.382675,3.053449,1.074312$

$\mathrm{H},-1.308218,-3.118725,-0.676692$

C, $0.09886,-1.47188,-0.66905$

H, $0.255902,-1.60927,-1.751134$

$\mathrm{N},-0.98317,0.75582,-0.253529$

C, $0.093291,0.031119,-0.431443$

C, $1.293581,-2.08712,0.067417$

H, 1.156668, -1.959032, 1.149301

$\mathrm{N}, 1.278652,0.734791,-0.420065$

C, $2.427985,0.102499,-0.43439$

C, $2.590322,-1.408737,-0.371661$

H, 2.827259, $-1.733322,-1.397562$

H, 1.34496, -3.163892, -0.124273

C, 3.788537, $-1.740242,0.526459$

H, 3.562037, -1.427107, 1.554076

$\mathrm{H}, 3.955961,-2.821935,0.551814$

C, $5.043485,-1.019359,0.034426$

$\mathrm{N}, 3.537753,0.908136,-0.548436$

C, $4.73686,0.400282,-0.398417$

$\mathrm{N}, 5.787267,1.242483,-0.702242$

H, 5.429517, $-1.538705,-0.856565$

C, 6.162788, $-0.963477,1.087371$

H, $6.424547,-1.981434,1.391569$

$\mathrm{H}, 5.779266,-0.452911,1.981034$

C, 7.394485, $-0.220291,0.558502$

H, 7.969731, $-0.891499,-0.098217$

C, $7.003208,0.930746,-0.350814$

C, $8.142124,1.751573,-0.947742$

O, 8.772293, 1.141811, - 1.846685

O, 8.318078, 2.895686, - 0.47089

C, 8.349263, 0.250621, 1.68104

H, 9.172857, 0.815047, 1.232889

$\mathrm{H}, 7.810408,0.953155,2.329628$

C, $8.91836,-0.898806,2.518029$

$\mathrm{H}, 9.621607,-0.517812,3.265163$

$\mathrm{H}, 8.134636,-1.444589,3.052475$

H, 9.455969, -1.616647, 1.888099

N9

C, $10.440886,0.134949,0.693073$

C, 10.069857, $-1.135669,1.468234$

N, 8.641183, -1.459397, 1.43888

C, 7.919917, -1.022751, 0.46851

$\mathrm{N}, 6.547706,-1.321021,0.551165$ 
C, 5.690588, $-0.590062,-0.092354$

N, 4.359966, $-0.980263,0.026419$

C, $8.388368,-0.221575,-0.739503$

C, 6.034416, 0.614846, -0.958991

C, $9.902542,0.056835,-0.734213$

C, $7.498343,1.034304,-0.804069$

C, $5.021937,1.72801,-0.663768$

C, 3.602217, 1.22023, -0.917233

C, $2.505675,2.130797,-0.352231$

$\mathrm{H}, 10.418236,-0.756714,-1.252258$

H, 10.113002, $0.978535,-1.288416$

$\mathrm{H}, 11.529336,0.266045,0.694932$

H, 7.626958, 1.629771, 0.109373

H, 7.795363, 1.669762, -1.645511

H, 5.881283, 0.288339, -2.000341

H, 5.12429, 2.044396, 0.382736

H, 2.624213, 2.208937, 0.736608

$\mathrm{H}, 8.146727,-0.82751,-1.624459$

$\mathrm{H}, 3.451662,1.141368,-2.006032$

H, 5.22571, 2.606256, -1.285744

$\mathrm{H}, 10.016343,0.997432,1.222314$

C, $3.402896,-0.183541,-0.362853$

H, 10.305839, - $0.970399,2.532918$

$\mathrm{N}, 10.802533,-2.298142,0.929906$

$\mathrm{H}, 11.78058,-2.220622,1.207634$

$\mathrm{H}, 10.44945,-3.131298,1.399065$

H, 2.60357, 3.14274, -0.759227

C, $1.128146,1.558615,-0.683913$

$\mathrm{H}, 0.942831,1.698754,-1.761082$

N, 2.125687, $-0.707917,-0.266597$

C, 1.078287, 0.057581, -0.440665

C, $-0.021019,2.219797,0.085697$

$\mathrm{H}, 0.135389,2.078994,1.163306$

$\mathrm{N},-0.135127,-0.59741,-0.415199$

C, $-1.25699,0.081998,-0.403544$

C, $-1.353417,1.598033,-0.329958$

$\mathrm{H},-1.593172,1.937826,-1.350502$

$\mathrm{H},-0.032058,3.298865,-0.099373$

C, $-2.525755,1.97251,0.584235$

$\mathrm{H},-2.311098,1.634105,1.606354$

$\mathrm{H},-2.643901,3.060221,0.623856$

C, $-3.812313,1.31857,0.082053$

$\mathrm{N},-2.39997,-0.679966,-0.4894$

C, $-3.579272,-0.131027,-0.313214$

$\mathrm{N},-4.649847,-0.965459,-0.538338$

$\mathrm{H},-4.132089,1.835773,-0.836886$

C, $-4.968853,1.372432,1.087875$

$\mathrm{H},-5.187327,2.410043,1.36059$

H, $-4.67168,0.853206,2.0084$

C, $-6.211828,0.707,0.497894$

H, $-6.632294,1.374616,-0.270042$

C, $-5.862691,-0.583621,-0.218034$

C, $-7.302808,0.409627,1.540185$

H, $-6.88496,-0.257243,2.304124$

$\mathrm{N},-6.873009,-1.443938,-0.605577$

$\mathrm{H},-7.585241,1.334891,2.051962$

C, $-8.519608,-0.253385,0.881367$

H, $-9.084143,-0.82375,1.630045$

C, $-8.08593,-1.272947,-0.155555$

C, $-9.16493,-2.21552,-0.676148$

O, $-9.430684,-3.148527,0.120478$

O, $-9.657199,-1.944377,-1.796034$

C, $-9.51306,0.758681,0.240576$

H, $-8.958509,1.44859,-0.407939$

$\mathrm{H},-10.194911,0.210207,-0.415855$

C, $-10.320282,1.550323,1.273797$

$\mathrm{H},-11.007712,2.241372,0.775841$

$\mathrm{H},-10.915932,0.880101,1.903329$

H, $-9.678457,2.143978,1.932411$ 
N10

C, 11.604121, 0.000119, 0.478467

C, $11.255777,-1.281289,1.259109$

N, 9.819946, -1.583035, 1.271883

C, $9.06995,-1.119081,0.335975$

N, 7.696297, -1.391299, 0.47028

C, 6.827461, $-0.639347,-0.132805$

$\mathrm{N}, 5.496081,-1.002427,0.043126$

C, $9.503737,-0.315125,-0.884695$

C, 7.160399, 0.561817, -1.009542

C, $11.021397,-0.062042,-0.931876$

C, 8.63544, 0.956796, - 0.904695

C, 6.175991, 1.690644, -0.682458

C, $4.741945,1.203199,-0.890872$

C, 3.675491, 2.139664, -0.311988

$\mathrm{H}, 11.507674,-0.872869,-1.487368$

H, $11.230905,0.85725,-1.489756$

$\mathrm{H}, 12.691968,0.130571,0.450816$

$\mathrm{H}, 8.807481,1.541427,0.008609$

H, 8.912211, $1.594711,-1.751181$

$\mathrm{H}, 6.968018,0.238539,-2.045465$

$\mathrm{H}, 6.315971,2.005739,0.360099$

$\mathrm{H}, 3.824403,2.234756,0.771797$

H, $9.218625,-0.908679,-1.765023$

$\mathrm{H}, 4.562182,1.112214,-1.974355$

$\mathrm{H}, 6.373024,2.565413,-1.311522$

$\mathrm{H}, 11.193168,0.862859,1.019211$

C, $4.537384,-0.190671,-0.312826$

$\mathrm{H}, 11.540059,-1.125059,2.308695$

$\mathrm{N}, 11.968668,-2.498473,0.835693$

$\mathrm{H}, 11.790035,-2.669029,-0.152984$

H, 12.971059, $-2.332915,0.914948$

H, 3.776906, 3.142904, -0.739286

C, $2.281582,1.582002,-0.596702$

H, 2.076286, 1.69318, -1.673709

$\mathrm{N}, 3.257448,-0.68891,-0.153745$

C, 2.214565, 0.089494, -0.307716

C, $1.160446,2.286221,0.175015$

$\mathrm{H}, 1.339164,2.180292,1.253158$

$\mathrm{N}, 0.995785,-0.544309,-0.213744$

C, $-0.119136,0.15069,-0.196255$

C, $-0.18987,1.670513,-0.188524$

H, $-0.442904,1.969377,-1.218716$

$\mathrm{H}, 1.160339,3.358419,-0.047069$

C, $-1.337379,2.106229,0.729183$

$\mathrm{H},-1.107877,1.811182,1.761535$

H, $-1.437961,3.196438,0.721261$

C, $-2.643494,1.451324,0.282515$

$\mathrm{N},-1.270649,-0.596949,-0.210298$

C, $-2.442241,-0.021514,-0.041483$

$\mathrm{N},-3.525533,-0.843644,-0.206579$

$\mathrm{H},-2.971578,1.927927,-0.655136$

C, $-3.777297,1.577617,1.307092$

$\mathrm{H},-3.972478,2.631457,1.530375$

H, $-3.467299,1.101934,2.246658$

C, $-5.044331,0.904418,0.780785$

$\mathrm{H},-5.485627,1.546626,0.003301$

C, $-4.732938,-0.420307,0.104399$

C, $-6.097927,0.658328,1.873789$

$\mathrm{H},-5.643109,0.051438,2.665072$

$\mathrm{N},-5.762914,-1.242961,-0.261462$

H, $-6.388348,1.610072,2.330896$

C, $-7.329189,-0.064893,1.319011$

H, $-7.808515,-0.640335,2.120426$

C, $-6.968362,-1.034298,0.212181$

C, $-8.402725,0.865326,0.702855$

$\mathrm{N},-7.990661,-1.76816,-0.332626$

$\mathrm{H},-8.724211,1.587043,1.459441$

H, $-7.957573,1.441693,-0.118425$

C, $-9.608372,0.06209,0.185037$ 
H, $-10.301812,-0.122609,1.019246$

C, $-9.214289,-1.332819,-0.268443$

C, $-10.349201,-2.287684,-0.626715$

O, $-10.961475,-2.72343,0.378673$

$\mathrm{O},-10.540769,-2.496298,-1.846219$

C, $-10.402788,0.800012,-0.919201$

H, $-11.193388,0.139543,-1.288817$

H, -9.732373, 0.983778, -1.768761

C, $-11.016224,2.120776,-0.444928$

$\mathrm{H},-11.69027,1.959781,0.403938$

H, -10.251446, 2.839011, -0.13266

H, $-11.595558,2.585674,-1.24872$

\section{References}

1. Xia, J. H.; Matyjaszewski, K., Controlled/"living" radical polymerization. Atom transfer radical polymerization catalyzed by copper(I) and picolylamine complexes. Macromolecules 1999, 32 (8), 2434-2437.

2. Tang, H. D.; Radosz, M.; Shen, Y. Q., CuBr2/N,N,N ',N '-tetra[(2-pyridal)methyl] ethylenediamine/tertiary amine as a highly active and versatile catalyst for atom-transfer radical polymerization via activator generated by electron transfer.

Macromol Rapid Comm 2006, 27 (14), 1127-1131.

3. Kubin, R. F.; Fletcher, A. N., Fluorescence Quantum Yields of Some Rhodamine Dyes. J Lumin 1982, 27 (4), $455-462$.

4. M. J. Frisch, G. W. T., H. B. Schlegel, G. E. Scuseria, M. A. Robb, J. R. Cheeseman, G. Scalmani, V. Barone, G. A.

Petersson, H. Nakatsuji, X. Li, M. Caricato, A. Marenich, J. Bloino, B. G. Janesko, R. Gomperts, B. Mennucci, H. P. Hratchian,

J. V. Ortiz, A. F. Izmaylov, J. L. Sonnenberg, D. Williams-Young, F. Ding, F. Lipparini, F. Egidi, J. Goings, B. Peng, A. Petrone,

T. Henderson, D. Ranasinghe, V. G. Zakrzewski, J. Gao, N. Rega, G. Zheng, W. Liang, M. Hada, M. Ehara, K. Toyota, R.

Fukuda, J. Hasegawa, M. Ishida, T. Nakajima, Y. Honda, O. Kitao, H. Nakai, T. Vreven, K. Throssell, J. A. Montgomery, Jr., J.

E. Peralta, F. Ogliaro, M. Bearpark, J. J. Heyd, E. Brothers, K. N. Kudin, V. N. Staroverov, T. Keith, R. Kobayashi, J. Normand,

K. Raghavachari, A. Rendell, J. C. Burant, S. S. Iyengar, J. Tomasi, M. Cossi, J. M. Millam, M. Klene, C. Adamo, R. Cammi, J.

W. Ochterski, R. L. Martin, K. Morokuma, O. Farkas, J. B. Foresman, and D. J. Fox Gaussian 09 Rev. A.02, Wallingford, CT, 2016.

5. Lee, C. T.; Yang, W. T.; Parr, R. G., Development of the Colle-Salvetti Correlation-Energy Formula into a Functional of the Electron-Density. Phys Rev B 1988, 37 (2), 785-789.

6. Becke, A. D., Density-Functional Thermochemistry .3. The Role of Exact Exchange. J Chem Phys 1993, 98 (7), 56485652.

7. Yanai, T.; Tew, D. P.; Handy, N. C., A new hybrid exchange-correlation functional using the Coulomb-attenuating method (CAM-B3LYP). Chem Phys Lett 2004, 393 (1-3), 51-57.

8. Cossi, M.; Rega, N.; Scalmani, G.; Barone, V., Energies, structures, and electronic properties of molecules in solution with the C-PCM solvation model. J Comput Chem 2003, 24 (6), 669-681. 
9. Dou, Q. Q.; Fang, X. T.; Jiang, S.; Chee, P. L.; Lee, T. C.; Loh, X. J., Multi-functional fluorescent carbon dots with antibacterial and gene delivery properties. $R s c \operatorname{Adv} \mathbf{2 0 1 5}, 5$ (58), 46817-46822.

10. Lamson, M.; Kopec, M.; Ding, H. J.; Zhong, M. J.; Matyjaszewski, K., Synthesis of Well-Defined Polyacrylonitrile by ICAR ATRP with Low Concentrations of Catalyst. J Polym Sci Pol Chem 2016, 54 (13), 1961-1968.

11. Kopeć, M.; Yuan, R.; Gottlieb, E.; Abreu, C. M. R.; Song, Y.; Wang, Z.; Coelho, J. F. J.; Matyjaszewski, K.; Kowalewski, T., Polyacrylonitrile-b-poly(butyl acrylate) Block Copolymers as Precursors to Mesoporous Nitrogen-Doped Carbons: Synthesis and Nanostructure. Macromolecules 2017, 50 (7), 2759-2767. 